\title{
SALUKO TOK AKE: KOMPOSISI TARI PEREMPUAN SUKU ANAK DALAM ANTARA ADAT DAN EMANSIPASI PEREMPUAN
}

\author{
Lucky Pesona Sari, Asril, Rasmida \\ Program Pascasarjana, Penciptaan Seni Tari \\ Institut Seni Indonesia Padangpanjang \\ Padangpanjang, Sumatra Barat \\ E-mail : sariluckypesona@gmail.com
}

\begin{abstract}
Abstrak
Artikel ini bertujuan untuk membahas fenomena perempuan Suku Anak Dalam di Merangin, Jambi yang terikat dengan aturan adat mereka dalam komposisi tari Saluko Tok Ake. Saluko adalah aturan-aturan adat untuk para perempuan pada Suku Anak Dalam di Merangin, Jambi yang telah ditetapkan dan diwariskan oleh nenek moyang mereka. Aturan-aturan untuk anak perempuan itu berupa larangan seperti: dilarang keluar rimba, dilarang mandi pakai sabun, dilarang belajar baca tulis, tidak boleh berbicara dengan lelaki kecuali pemangku adat dan keluarga mereka, dilarang memakai kosmetik, dilarang memakai kemben bagi perempuan remaja, perempuan dewasa memakai baju kecuali ketika temenggung berada di lokasi perkampungan hanya memakai kodek ( bawahan ). Mereka tetap bertahan dan sangat patuh terhadap aturan-aturan adat itu. Fenomena ini ditafsirkan dalam perspektif emansipasi wanita yang tampak bertolak belakang seperti mengorbankan hak-hak perempuan ke dalam bentuk karya komposisi tari yang memakai tipe murni, didukung dengan penggarapan gerak, simbol, ekspresi, musik dan artistik berlatar belakang SAD.
\end{abstract}

Kata Kunci: Saluko Tok Ake, saluko, Suku Anak Dalam, emansipasi wanita, komposisi tari.

\section{Abstract}

The cultural phenomenon of Suku Anak Dalam especially Saluko or the rules of women in the Suku Anak Dalam, where women in Suku Anak Dalam adhere to the rules that have been built from ancestors despite sacrificing Women's Human Rights (emancipation of women), they still survive and are very obedient against the existing rules, rules for women in the Suku Anak Dalam such as: girls are prohibited from going out to the jungle, are prohibited from bathing with soap, are forbidden to learn how to read and write, may not talk to men except customary holders and their families, prohibited from using cosmetics, for women adolescents wear kemben, adult women wear clothes except when the Tomonggong is at the location of the village, this will be interpreted into a dance composition work that uses a pure type, supported by the cultivation of movements, symbols, expressions, music and artistic in order to become a whole dance composition work set in the background behind the In Sukun Anak Dalam.

Keywords: Saluko Tok Ake, saluko, Suku Anak Dalam, women's emancipation, dance composition.

\section{PENDAHULUAN}

Orang Rimba merupakan sebutan dari komunitas adat yang hidup dalam hutan di Provinsi Jambi. Sebutan orang rimba menurut mereka merupakan jalan kehidupan mereka dari sejak nenek moyangnya, dengan menggantungkan hidup pada hutan dan hasil-hasil hutan. Dalam menjalani kehidupan sehari-hari orang rimba berkomunikasi dengan orang 
luar, karena ada hal yang saling Andar Indra Sastra, 2019: 2 ).

menguntungkan. Hal yang saling Kalau kita lihat dari sudut pandang menguntungkan seperti kebun sawit yang sistem mengelola suatu kampung, mereka dimiliki orang luar bisa dijaga oleh orang hampir serupa dengan masyarakat luar rimba, sedangkan bagi orang rimba (orang terang), seperti: undang-undang mereka mendapatkan tempat di kebun (aturan adat), meliter (pemencak), jajaran sawit tersebut. Bagi masyarakat Jambi hukum (teliti duo bleh), ketua rombongan sebutan orang rimba disebut juga Suku (temenggung), pemangku agama Kubu. Kubu diartikan hidup liar, kotor, (pemucuk cekung) dan sebagainya. Kalau bau, penuh dengan kekuatan magis, ditelaah Suku Anak Dalam ini mempunyai bodoh dan tertutup, maka itu penyebutan aturan-aturan yang harus diikuti kubu sangat ditantang oleh Orang Rimba, sebagaimana saloko (undang) adat dan dengan lantang menyebut identitas mereka. Menurut Penanguk ${ }^{1}$ Suku Anak mereka sebagai Orang Rimba (Ari Dalam "Jangon melongor seloko adat, ka Tonang, 2008: 1). a adat mementok sosok anak cucu ake"

Bukit Dua Belas yang berada di yang artinya jangan melanggar aturan Provinsi Jambi tepatnya di Kabupaten adat, karena adat membentuk sosok (jati Merangin, merupakan tempat tinggalnya masyarakat Suku Anak Dalam yang diri) anak cucu kita.

Saloko adat menjadi pedoman hidup biasanya disebut Suku Kubu atau Orang dan jati diri Suku Anak Dalam terbentuk Rimba. Menurut sejarahnya nenek dari aturan-aturan yang berasal dari moyang Suku Anak Dalam berasal dari nenek moyangnya. Aturan-aturan itu lebih Minangkabau, ada di antara para pemikir banyak diberlakukan pada perempuan budayawan, tokoh masyarakat, para Suku Anak Dalam yang masih melakukan akademisi-baik sebagai orang ritual dan sesuai dengan kebiasaan Minangkabau maupun yang mengaku kehidupan mereka, seperti: Melangun sebagai orang Melayu di luar (mencari tempat tinggal baru), bebalai Minangkabau memaklumatkan bahwa (membuat panggung untuk ritual para "tak Melayu tak Islam" atau yang dukun), tarik rento (sanksi untuk dikatakan orang Melayu itu identik perempuan), besesandingon (ritual dengan Melayu Riau, Melayu Jambi, pengobatan Suku Anak Dalam), dan Melayu Palembang, dan Melayu Deli sebagainya (Pengendum masyarakat Suku maupun sebutan lain yang dikaitkan dengan wilyah geografis di Nusantara ini ( ${ }^{1}$ Penanguk adalah salah satu masyrakat Suku Anak Dalam. 
Anak Dalam, wawancara 6 Maret 2017, panjang). (Pengendum masyarakat Suku Bukit Dua Belas, Merangin, Jambi ).

Anak Dalam, wawancara 6 Maret 2017,

Aturan-aturan yang lain ringan namun cukup unik seperti: anak perempuan dilarang keluar rimba, dilarang mandi pakai sabun, dilarang belajar baca tulis, tidak boleh berbicara dengan lelaki kecuali pemangku adat dan keluarga mereka, dilarang memakai kosmetik, bagi perempuan remaja memakai kemben, perempuan dewasa memakai baju kecuali ketika temenggung berada di lokasi perkampungan hanya boleh memakai kodek (hanya penutup bagian bawah), perempuan tidak boleh disentuh kalau belum dinikahi, dilarang menikah dengan Orang Luar (orang terang), sedangkan lelaki boleh menikah dengan perempuan luar, dilarang memakai alas kaki, perempuan hamil dilarang berfoto atau dilukis, dilarang berobat ke Puskemas atau Rumah Sakit, dilarang makan daging kerbau, sapi, kambing, dan ayam.

Semua aturan-aturan tersebut sangat dipatuhi dan telah membentuk jati diri perempuan Suku Anak Dalam. Mereka tegar menerima aturan-aturan tersebut, yang telah digariskan oleh nenek moyang mereka. Jika salah satu masyarakat Suku Anak Dalam melanggar aturan, maka mereka diberi sanksi sesuai dengan pelanggaranya, seperti tunjuk ajor (denda dua puluh lembar kain
Bukit Dua Belas, Merangin, Jambi ).

Seiring perkembangan zaman, saat ini perempuan Suku Anak Dalam sudah menerima pengaruh luar yang didapat dari kaum pria Suku Anak Dalam yang boleh keluar dari rimba. Pengaruh inipun hanya didapatkan dari hasil cerita secara lisan dalam artian mereka tidak melihat langsung hal yang terjadi di luar tersebut.

Berdasarkan latar belakang di atas, pengkarya terinspirasi mengangkat fenomena Suku Anak Dalam ini menjadi sebuah karya tari. Hal ini disebabkan karena pengkarya melihat perempuan Suku Anak Dalam masih menjunjung tinggi aturan yang telah ada dari nenek moyang mereka, dan kepatuhan mereka terhadap aturan-aturan tersebut. Di sisi lain fenomena yang terjadi dewasa ini, generasi sekarang sudah banyak melanggar aturan-aturan yang ada. Seperti seorang anak tidak patuh kepada orangtuanya, siswa tidak patuh kepada gurunya, masyarakat ada yang tidak lagi menjalankan adat dan budayanya.

Untuk menjaga orisinalitas karya perlu melihat pada karya-karya sebelumnya yang memiliki kesamaan konsep dengan karya yang digarap. Agar tidak terkesan meniru/plagiat pada karya sebelumnya, pengkarya mengamati beberapa karya sebagai bahan 
perbandingan. Karya Raflesia Merina Tahun 2013, yang berjudul "Rimba AbuAbu" yang ditampilkan untuk persyaratan ujian Tugas Akhir S2 di Pascasarjana ISI Padangpanjang. Merina memfokuskan penggarapan karyanya pada hilangnya tempat tinggal Suku Anak Dalam, tipe karya Rimba Abu-Abu ini memakai tipe dramatik, tema sosial budaya, dengan memakai properti ranting pohon dan bilahan kayu.

Karya Tri Putra Mahardika, tahun 2015, yang berjudul "Ukar Delom Bungen.” Mahardika memfokuskan penggarapan karya pada ritual pengobatan besale yang dilakukan oleh Suku Anak Dalam. Karya Ukar Delom Bungen memakai tipe abstrak, tema ritual, dengan memakai properti tanah dan bibit pohon.

Deni Mayosta tahun 2016 "Halom Helang” yang ditampilkan dalam event PESIMINAS Ke-13 di Kendari. Penggarapan karya ini difokuskan pada ritual pengobatan perempuan Suku Anak Dalam, di mana dalam ritual ini perempuan yang mengidap penyakit akan diasingkan dari kelompok dan dimasukkan dalam sebuah kurungan (kerengkeng). Karya Helom Helang ini memakai tipe dramatik, tema sosial budaya, dengan memakai properti kerangkeng.

Dari ketiga karya di atas, tampak bahwa karya yang pengkarya garap berbeda dari fenomena, fokus penggarapannya, busana, penggunaan properti, dan orientasi atau tipe karya. Pengkarya memokuskan penggarapan pada masalah atura-aturan yang dimiliki oleh kaum perempuan Suku Anak Dalam yang telah digariskan dari nenek moyang mereka yang sangat mereka patuhi.

Untuk menciptakan sebuah karya seni tari, dibutuhkan sebuah riset dan sumber tertulis yang terkait. Buku yang berjudul "Orang Rimba Menentang Zaman" ( Ari Tonong : 2010) yang menjelaskan tentang kehidupan Suku Anak Dalam yang menentang aturanaturan. Untuk membantu penulisan Jurnal ini, pengkarya menggunakan teori Jacqueline Smith "Dance Composition” A Practical Guid for Teacher ("Komposisi Tari” Sebuah Petunjuk Praktis bagi Guru, terjemahan Ben Suhasto) pada tahun 1985. Jacqueline Smith banyak menerangkan tentang komposisi-komposisi tari dengan jelas. (Jaqueline Smith.1985.2 )

\section{HASIL DAN PEMBAHASAN}

\section{Saluko Adat dan Emansipasi Wanita}

Seorang pengkarya seni ada beberapa yang memilih melakukan sebuah perenungan untuk mencari sebuah inpirasi. Dalam pencarian berbagai sumber referensi dan ide-ide dalam penciptaan karya seni, pengkarya pun 
sbaiknya melakukan riset terhadap untuk perempuan suku anak dalam yang fenomena yang berkembang di sekitarnya. sangat mematuhi aturan yang telah dibuat (Lovia Triyuliani. 2019. 65). Suku Anak oleh nenek moyangnya, mereka sangat Dalam yang tinggal di Provinsi Jambi tegar menerima aturan yang telah selalu menggantungkan hidup pada hutan digariskan kepada perempuan suku anak dan hasil hutan dalam menjalani dalam. Pada saat zaman modern sekarang kehidupan sehari-hari. Suku Anak Dalam ini perempuan suku anak dalam sudah berkomunikasi dengan orang luar karena bisa menerima pengeruh luar yang didapat ada hal yang saling menguntungkan bagi dari kaum pria tanpa keluar dari rimba, Suku Anak Dalam dan orang luar. Dalam sudut pandang sistem pengelolaan suatu kampung, mereka hampir serupa dengan masyarakat luar yang memiliki undangpengaruh inipun hanya bisa didapat dari mulut ke mulut tanpa melihat langsung perkembangan zaman saat ini.

Salah satu penciptaan yang ada di undang (aturan adat), jajaran hukum dunia adalah manusia, yang mana (teliti duo bleh), ketua rombongan manusia berbeda dengan pembuatan (temenggung), pemangku adat (pemucuk yang lainnya. Manusia memiliki cekung), dan lain sebagainya. Suku anak kelebihan dan dimuliakan oleh Allah SWT. dalam ini mempunyai aturan-aturan yang Manusia diciptakan dengan dua jenis harus diikuti sebagaimana saluko kelamin yang berbeda, yaitu disebut Laki(undang) adat mereka, aturan-aturan Laki dan Perempuan. Keduanya memang yang ringan bagi mereka namun cukup berbeda dari segi jenis dan bentuk. unik bagi orang luar, seperti: anak Sempat tertulis di literatur keislaman perempuan dilarang keluar rimba, jaman dahulu pada peradaban Yunani, dilarang mandi pakai sabun, dilarang perempuan merupakan alat pemenuh belajar baca tulis, dilarang berkomunikasi naluri seks laki-laki. Pandangan ini dengan orang luar, dilarang memakai martabat perempuan sama dengan kosmetik, dilarang memakai alas kaki, pembantu mereka menganggap dilarang berobat ke Puskesmas atau perempuan sebagai sumber laknat Rumah Sakit, dilarang bersentuhan karena dialah yang menyebabkan adam dengan laki-laki kalau belum dinikahi, diusir dari surga. Pandangan masyarakat dilarang menikah dengan orang luar, bagi pada masa lalu tidak juga lebih baik perempuan dewasa memakai kemben sepanjang abad pertengahan, nasib atau kain dan sebagainya. perempuan tetap sangat , Aturan-aturan tersebut hanya memprihatinkan. (Edi Susanto, 2014.30 ) 
Namun seiring perkembangan agar-agar wanita disejajarkan dengan zaman wanita sudah tidak kaum pria dalam kehidupan, pekerjaan, didiskriminasikan, hal ini karena dan kemajuan asalkan tidak kebablasan. keberadaan gerakan emansipasi wanita. Emansipasi adalah istilah yang digunakan untuk menjelaskan jumlah usaha untuk mendapatkan hak politik maupun persamaan derajat, sering bagi kelompok yang tak diberi hak secara spesifik, atau secara lebih umum dalam pembahasan masalah seperti itu. (Achmad Syafi,l Ma'ani, 2013.12 ).

Pada hakikatnya, perempuan yang

\section{Tahap Perwujudan}

Pengkarya melakukan beberapa tahap dalam mewujudkan karya tari ini. Adapun tahap-tahap yang dilakukan sebagai berikut.

\section{Persiapan}

Pada tahap awal pengkarya melakukan persiapan dengan cara melakukan pengamatan terhadap telah bersuami berbakti kepada suami, keberadaan dan fenomena yang terjadi pria guru rumah tangga, menjadi guru pada Suku Anak Dalam. Dilanjutkan bagi anak-anak supaya anaknya menjadi dengan mencari dan mengumpulkan anak yang berbakti dan berguna bagi berbagai informasi dan data dengan keluarga, masyarakat, nusa dan bangsa, melakukan wawancara kepada pemangku kita dengar istilah "Di balik lelaki hebat adat yang mereka sebut Temenggung ada perempuan yang hebat pula. (Arvind (ketua adat). Beliau juga membantu proses Sharma, 2002. 7 ) penelitian pengkarya terhadap Suku Anak

Emansipasi wanita juga bisa Dalam. Setelah itu pengkarya melakukan diartikan sebagai suatu usaha untuk pencarian data di perpustakaan berupa menuntut persamaan hak-hak kaum referensi dan rekaman karya-karya yang wanita terhadap hak-hak kaum pria di terkait dengan objek material dan orientasi semua bidang seumur hidup. Emansipasi penggarapannya. Sumber dalam bentuk wanita mengharapkan memberi wanita referensi difokuskan pada buku-buku teori kesempatan bekerja, belajar, dan berkarya yang mendukung karya seperti, Koreografi seperti halnya para pria, seimbang \& Kreativitas, komposisi tari, dan dengan kemampuannya. Pengertian koregrafer kelompok serta ditunjang oleh sama di sini lebih dipersepsikan pada referensi yang terkait dengan Suku Anak kata sejajar karena tidak bisa dipungkiri Dalam. Berdasarkan hasil penelitian yang perempuan dan laki-laki jelas berbeda. dilakukan, pengkarya menganalisis Para penyeru emansipasi wanita ingin fenomena Suku Anak Dalam dan 
kemudian menetapkan hasil analisis yang telah didapat selama proses pengkarya terhadap fenomena aturan- eksplorasi. Karya ini digarap dalam tiga aturan yang terjadi pada perempuan Suku alur garapan suasana. Bagian satu Anak Dalam sebagai gagasan utama menggambarkan aktivitas perempuan dalam rancangan konsep karya tari yang Suku Anak Dalam yang berada di dalam akan pengkarya garap.

\section{Ekspolasi Gerak}

Dalam tahapan ini pengkarya melakukan pengembangan gerak dari Tari Si Along, sebuah tari ritual Suku Anak Dalam. Ritual ini bertujuan untuk meminta izin pada roh nenek moyang mengambil madu di pohon Si Along. Pohon Si Along ini berdiameter sekitar 4 meter dan tinggi sekitar 20 meter, pohon ini dipercaya oleh Suku Anak Dalam sebagai pohon sakral.

Masyarakat yang belum menikah disuruh oleh Temenggung melakukan ritual tari Si Along ini, dilakukan dengan cara mengelilingi pohon

$\mathrm{Si}$ Along tersebut, berjalan jongkok, berjalan bungkuk sambil melambaikan kedua belah tangan ke atas dan ke bawah dan kepala menghadap ke bawah. Proses pengembangan gerak harus sesuai dengan konsep dan melakukan pembakuan gerak dengan hitungan yang beragam, tetapi tidak menghilangkan gerak tradisi keseharian.

\section{Komposisi/Pembentukan}

Pada tahapan ini pengkarya telah tempo tinggi, dan pada akhirnya anti melakukan beberapa tahap untuk klimaks, agar tarian dan musik berbaur menyusun atau merangkai gerak-gerak maka dilakukan latihan ekstra untuk 
bagian ini, karena butuh konsentrasi dan hafalan yang kuat agar tercapainya pesan yang disampaikan pada bagian tiga ini.

Suatu karya yang utuh harus melalui latihan bagian per bagian dan pada akhirnya dilakukan latihan secara utuh, baik musik, propeti dan lighting. Pembimbing karya berperan sebagai pemberi masukan agar karya ini mencapai titik sempurna.

\section{Evaluasi}

Pada tahapan ini pengkarya melakukan evaluasi karya ini secara utuh dari bagian awal hingga akhir, sehingga pengkarya bisa melihat kekurangan atau kelebihan pada bagian-bagian tertentu. Pada proses evaluasi juga dilakukan bimbingan dengan dosen pembimbing. Beberapa koreksi dan perubahan dari pembimbing seperti, penari melakukan gerak kurang rampak, ekspresi kurang terlihat, dan kurang maksimal dalam melakukan gerakan, penggabungan dengan musik belum cocok, ekspresi suasana belum terdukung oleh musik, lighting yang kurang cocok warna cahayanya dan propeti yang kurang di eksplor secara maksimal.

\section{Judul Karya}

Dalam menentukan judul yang berlatar belakang dari aturan-aturan perempuan Suku Anak Dalam, pengkarya memilih dengan judul "Seloko Tok Ake" yang artinya aturan untuk aku. Di dalam suku anak dalam "seloko" yaitu aturanaturan yang masih dipakai dari nenek moyang hingga saat ini, "Tok" yang berarti untuk dan sedangkan "Ake" merupakan aku, dalam artian aku disini menganalogikan perempuan Suku Anak Dalam.

\section{Konsep Karya}

Karya ini yang terinpirasi dari aturan-aturan Suku Anak Dalam yang masih digunakan hingga saat ini, yang akan mengajarkan bagi sebagai seorang perempuan yang mengikuti zaman pada saat ini, jangan melupakan aturan-aturan yang telah diberikan menurut tradisi. Aturan-aturan yang berlaku terhadap perempuan Suku Anak Dalam menjadi rangsangan cipta bagi pengkarya untuk menjadikannya sebuah karya seni tari. Rangsang tari yang dipakai, yaitu rangsang visual, rangsang visual dapat timbul dari gambar, obyek, pola, wujud. Gambaran visual berasal dari latarbelakang dan kehidupan kesehariannya. (Jacqueline smith.1985. 22 ). Berdasarkan ketertarikan pengkarya terhadap fenomena tersebut, perempuan identik dengan pemakaian kosmetik, memperhatikan penampilan, pendidikan dan mengikuti perkembangan zaman. Akan tetapi, perempuan pada Suku Anak Dalam masih mematuhi aturanaturan yang telah dibuat oleh generasi sebelumnya, sehingga hal inilah yang merangsang pengkarya untuk menjadikan 
fenomena ini sebagai karya seni tari. perempuan Suku Anak Dalam , pesan yang Untuk melakukan transformasi dan akan disampaikan bersifat global maka mengaplikasikan konsep yang dipilih ke dari itu memilih tema tari kehidupan.

dalam karya, maka dilakukan penafsiran

Tipe yang akan digunakan untuk dari kejadian yang sebenarnya terjadi di lapangan secara kasat mata. Karya ini menghasilkan bentuk tari kelompok dan karya tari kreasi baru.

Karya ini digarap dalam tiga alur garapan suasana. Bagian satu menggambarkan aktivitas perempuan Suku Anak Dalam yang berada di dalam hutan dan menjaga tempat tinggal mereka, dengan menghadirkan suasana sunyi dan tenang. Bagian dua menggambarkan pempimpin yang menjaga perempuan Suku Anak Dalam yang selalu mereka pegang teguh hingga penggarapan konsep ini, yaitu memakai tipe murni. Tipe murni merupakan sebuah tari yang rangsang awalnya kinetik atau gerak, hanya semata-mata memfokuskan gerak dari tubuhnya sendiri atau gerak dari sumber tertentu. Tipe murni dirancang berdasarkan pengembangan motif gerak simbolis, tetapi juga dapat dipersepsi seolah-olah representatif. (Robby Hidayat. 97-98 ) Pengkarya akan menyampaikan pesan yang harus akurat dan jelas, maka dari itu memilih tipe murni.

Gerak yang disajikan dalam proses saat ini yang dihadirkan dengan aktivitas penggarapan tari ini berdasarkan dari dan suasana sakral. Bagian tiga peristiwa dan aktifitas Suku Anak Dalam menggambarkan kekompakkan mereka seperti mencari kayu, memasak, dan dalam menjalani aturan-aturan yang telah berkomunikasi yang diinterpretasikan ke diberikan oleh pemimpin adat mereka, yang dihadirkan dengan damai dan tenang.

dalam bentuk gerak baru, sehingga akan tercapainya sebuah karya seni tari yang berlatar belakang Suku Anak Dalam.

Tema yang digunakan dalam karya Peristiwa dan aktifitas Suku Anak Dalam ini yaitu tema kehidupan. Alasan memilih ini diinterpetasikan ke dalam sebuah tema kehidupan, dikarenakan konsep bentuk gerak baru yang mempunyai yang dijadikan ide gagasan pada karya ini merupakan suatu kehidupan tradisi atau simbol. Simbol merupakan sebuah pusat perhatian yang tertentu, sebuah sarana kebiasaan yang telah digunakan dan komunikasi, dan landasan pemahaman disepakati oleh Suku Anak Dalam dari bersama. (F.W. Dillistone. 2002. 15. ) zaman nenek moyang mereka hingga saat Simbol yang digunakan dalam karya, yakni ini. Aturan tersebut berlaku untuk semua simbol gerak cara berjalan, duduk, dan 
berdiri. Pengkarya menyampaian pesan atau simbol melalui gerak tari; pijakan gerak juga sangat penting karena karya ini terfokus pada pengarapan peristiwa, pesan dan simbol. Gerak yang sudah dikembangkan pada gerak berjalan, duduk, dan berdiri, salah satu contohnya berasal dari pengembangan cara berjalan perempuan Suku Anak Dalam dengan posisi badan bungkuk.

Penari merupakan pendukung terpenting dalam sebuah karya tari, satu pendukung untuk membangun karena peran penari dalam sebuah karya suasana yang dihadirkan dalam tari untuk menyampaikan pesan yang pertunjukkan tari. Tari tidak terlepas dari akan disampaikan dalam sebuah karya musik karena tanpa adanya musik tari ini tari. Dalam karya "Seloko Tok Ake" tidak akan tersampaikan apa yang memakai sembilan orang penari diinginkan oleh pengkarya sendiri. Musik perempuan, dalam penggarapannya yang dihadirkan berlatar belakang dari formasi penari kelompok bergerak budaya Suku Anak Dalam. Instrument bersama, formasi ini menunjukan yang dipakai seperti gendang redap yang kekuatan pada aspek gerak bersama. menyimbolkan identitas Suku Anak Kekompakan memberikan kesan yang Dalam, untuk perkusi melodis seperti kuat tentang penggambaran kulintang berfungsi untuk memberi variasi kebersamaan, kekuatan, dan memberikan sekaligus untuk identitas Provinsi Jambi. fokus perhatian yang besar pada Musik bagian vokal memakai lirik yang penonton. (Robby Hidayat. 2011. 67 ) berlatar belakang Bahasa Suku Anak Selain penari kelompok, juga Dalam agar tercapai pesan dan suasana menggunakan tokoh pada saat tertentu yang disampaikan. Penggarapan musik untuk menggambarkan pemimpin dan tari menggunakan beberapa media penari tokoh melebur menjadi penari pendukung seperti cello, biola, flute, kelompok nantinya. Dalam pemilihan gandang tambua dan contra bass, dan penari untuk karya ini, tidak terlepas dari memakai musik tekno. Dalam pendekatan penari yang sudah lama penggarapan musik tari ini bukan hanya memiliki hubungan emosional dengan sekadar pengiring tari, suasana, dan 
ilustrasi saja, tetapi menjadi bagian yang tak terpisahkan dari karya tari.

Pengkarya menghadirkan suasana bagian pertama sunyi dan tenang; alat musik dan media yang digunakan adalah laptop, alat tiup, gendang melayu dan vokal. Bagian dua suasana dihadirkan sakral, alat musik yang digunakan adalah instrumen perkusi dan melodi seperti kulintang, gandang tambua, kompang, gong, vokal, violin, cello dan contrabass. Bagian tiga suasana yang dihadirkan damai dan tenang, digunakan alat musik, yaitu violin, cello, contrabass, vocal, dan alat tiup.

Tata rias dan busana merupakan salah satu dari pendukung karya untuk memperkuat sebuah karya seni tari. Dalam sebuah karya seni tari tata rias yang digunakan oleh seorang penari sesuai dengan watak atau peran yang ditampilkannya. Pengkarya menggunakan konsep rias yang sesuai dengan keseharian Suku Anak Dalam, seperti memakai rias cantik panggung tetapi menggunakan foundation berwarna coklat, eye shadow berwarna coklat, dan sedikit olesan minyak zaitun agar wajah tampak lebih mengkilat, sehingga terkesan eksotis.

Busana yang digunakan yaitu kain panjang bewarna merah hati dengan motif kain batik jambi yang dijadikan kemben yang panjangnya sampai di

bawah lutut. Kemudian dipadukan dengan blus kaos ketat lengan panjang tangan yang berwarna kulit. Bahan yang dipakai tidak terlepas dari kenyaman penari agar dalam melakukan gerak tidak terganggu. Pada saat melakukan observasi ke Bukit Dua Belas Dalam : pengkarya melihat langsung pakaian yang digunakan perempuan Suku Anak ; mereka hanya memakai kain panjang yang dijadikan penutup bagian dada.

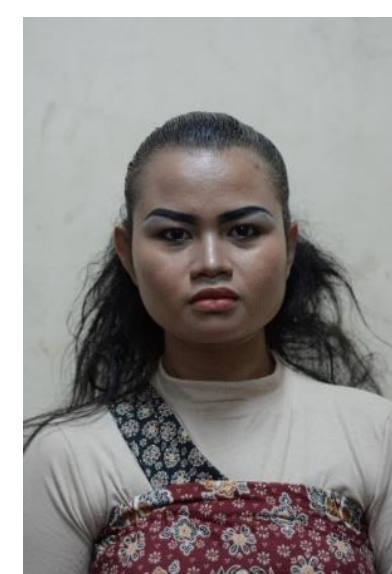

Gambar 1

Tatarias penari kelompok (Dokumentasi: Lucky Pesona S)

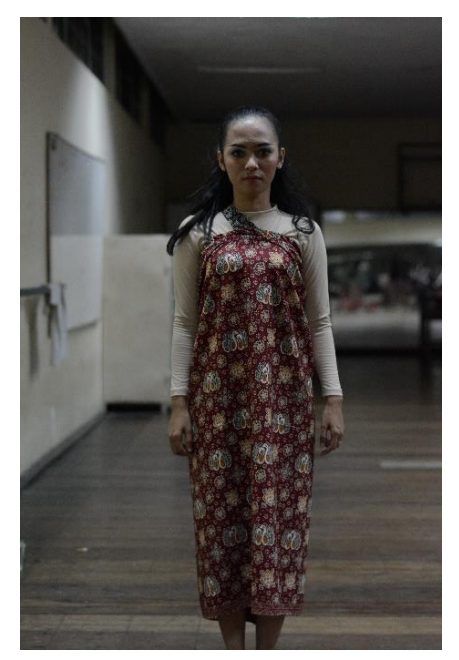

Gambar Foto 2 busana tari (Dokumentasi: Lucky Pesona S) 
Karya ini dipertunjukkan di menyimbolkan aturan-aturan perempuan Auditorium Boestanoel Arifin Adam. Suku Anak Dalam. Properti ambung Pentas yang digunakan adalah pentas (keranjang yang terbuat dari rotan) prosenium, dan arena bentuk $\mathrm{U}$ digunakan untuk memberikan simbol (penonton mengitari pentas membentuk kegiatan dan kebiasaan perempuan dalam huruf U). (Pramana Padmodarma. 1988. mencari ranting-ranting sebagai bahan 36). Pentas prosenium menyimbolkan masak mereka yang diletakkan di dalam sebagaimana mestinya Suku Anak Dalam ambung dan dua lapik (tikar) sebagai alas menjalani aktivitas mereka di dalam tempat mereka tidur. Kemudian setting hutan. Pengkarya menggunakan yang digunakan memakai tanah merah panggung prosenium hanya sebagai lantai bahwasanya mereka tidak menggunakan setengah, agar terlihat memakai alas kaki langsung berpijak pada lebih jelas aktivitas perempuan Suku tanah, dan memakai daun-daun dan Anak Dalam, sedangkan arena sebagai ranting-ranting layaknya di tempat tinggal sebuah pandangan terhadap perempuan mereka (hutan).

Suku Anak Dalam dengan wujud dekat, khususnya perempuan Suku Anak Dalam yang masih memegang teguh dan mematuhi aturannya.

Peranan tata cahaya stage lighting sangat mendukung suatu bentuk pertunjukan karya ini. Pengkarya menggunakan general light bersifat penerangan sepenuhnya, (Y Sumandiyo Hadi. 2003. 92), karena konsep garapan ini menggambarkan kekompakan dan kepatuhan perempuan Suku Anak Dalam dalam menjalani aturan-aturan yang diberikan oleh pemimpin mereka.

Properti yang digunakan yakni, kain panjang polos bewarna merah berukuran sepuluh meter. Kain itu diletakkan di tiang kanan dan kiri terbentang di arena sebagai pagar yang

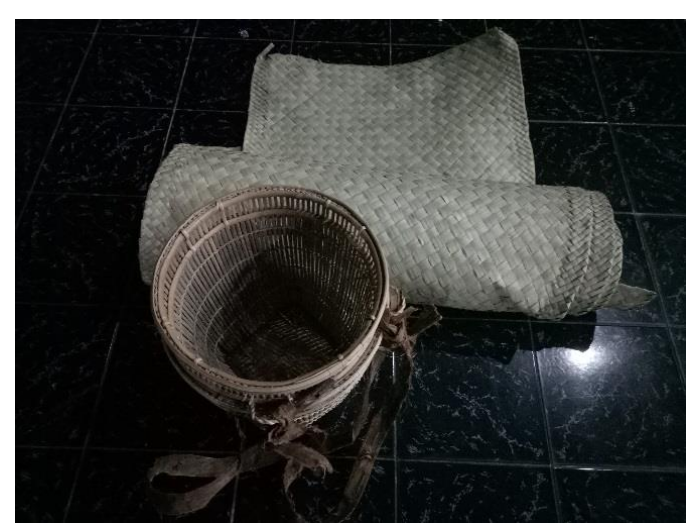

Gambar 3

Properti tari (dokumentasi: Lucky Pesona S) 
MEL.AYU ARTSAND JOURNAL

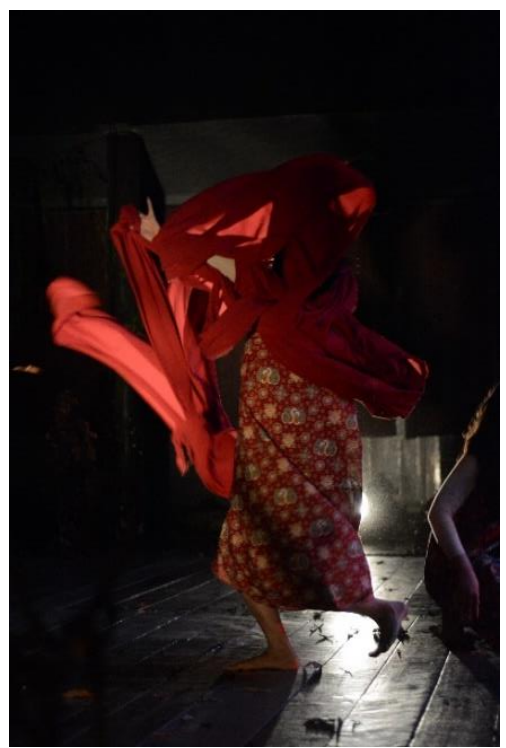

Gambar 4.

Penari menggunakan kain panjang (dokumentasi: Rayhan Redha Febrian)

\section{PENUTUP}

Kaum perempuan Suku Anak

Dalam akan tetap mengikuti dan menaati tradisi serta aturan yang ada di tengah sekelompok suku anak dalam aturan itu telah menjadi suatu tradisi yang ada sejak nenek moyang secara turun menurun hingga sampai saat ini, hal tersebut akan tetap dipegang teguh meskipun zaman sudah berkembang. walaupun kaum perempuan suku anak dalam tidak pernah keluar dari ruang lingkup mereka, perempuan suku anak dalam mengetahui perkembangan zaman yang didapat dari kaum pria yang boleh keluar dari rimba, informasi yang didapat hanya secara lisan

\section{Vol. 4, No. 1, April, 2021}

tanpa melihat langsung. Jati diri perempuan suku anak dalam terbentuk dari aturan-aturan yang telah ada, dari itu mereka tetap mengikuti dan memegang teguh aturan yang telah digariskan dari nenek moyangnya.

\section{DAFTAR PUSTAKA}

Aritonang, Robert dkk. (2008). Orang

Rimba Menentang Zaman, Jakarta:

WARSI

Dillistone, F, W. 1986. The Power Of Symbols. Terjemahan A. Widayamartaya.

Daya Kekuatan Simbol. Yogyakarta : Kanisius

Hadi, Sumandiyo. 2003. Koreografer Kelompok. Yogyakarta: Pustaka

Hidayat, Robby. 2011. Koreografi dan Kreatifitas. Yogyakarta : Media Kendil.

Padmodarmaya, Pramana, 1988, Tata Dan Teknis Pentas. Yogyakarta Pustaka Book.

Merina, Raflesia. 2013. Rimba Abu-Abu. Laporan Karya Tugas Akhir Pasca Sarjana. Padangpanjang : ISI Padangpanjang.

Putra, Mahardhika, Tri. 2016. Ukar Delom Bungen. Laporan Karya Tari. ISI Padangpanjang.

Sharma, Arvind. 2002. Perempuan Dalam Agama-Agama

Dunia. Perguruan Tinggi Agama Islam Depertemen Agama RI.

Sastra, Andar, Indra, 2018, Suku Melayu: Sistem Matrilineal dan Budaya Perunggu di Minangkabau. Jurnal Melayu Art And Performance Journal. Vol. 1, No. 1, April, 2018

Smith, Jacquelin. 1985. "Dance 
Composition" A Practical Guide for teachers. Terjemahan Ben Suharto. Komposisi Tari” Sebuah Petunjuk Praktis bagi Guru. Yogyakarta : Ikalasti.

Susanto, Edi. 2014 Dimensi Studi Islam Kontemporer.Surabaya: CV Salsabila.

Triyuliani, Lovia. 2019. Mutualisme. Sebuah Karya Tari Yang Terinspirasi

Dari Fenomena Sosial Masyarakat pengguna jamban Di Muaro Bungo. Jurnal Melayu Art And Performance Journal. Vol.2, No. 1. April.2019. 